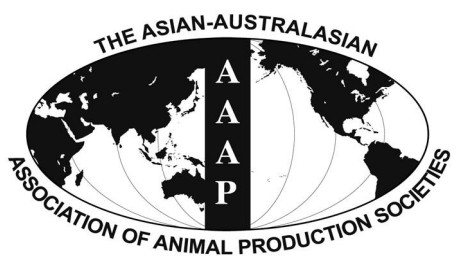

\title{
Estimation of Growth Curves and Suitable Slaughter Weight of the Liangshan Pig
}

\author{
Jia Luo ${ }^{1, a}$, Huaigang Lei ${ }^{1,2, a}$, Linyuan Shen ${ }^{1}$, RunlinYang ${ }^{3}$, Qiang Pu ${ }^{1}$, Kangping $\mathrm{Zhu}^{4}$, \\ Mingzhou $\mathrm{Li}^{1}$, Guoqing Tang ${ }^{1}$, Xuewei $\mathrm{Li}^{1}$, Shunhua Zhang ${ }^{1, *}$, and $\mathrm{Li} \mathrm{Zhu}{ }^{1, *}$ \\ ${ }^{1}$ College of Animal Science and Technology, Sichuan Agricultural University, Ya'an 625014, China
}

\begin{abstract}
The Liangshan pig is a traditional Chinese small-sized breed; it has a relatively long feeding period and low meat production ability but superior meat quality. This study utilized three non-linear growth models (Von Bertalanffy, Gompertz, and logistic) to fit the growth curve of Liangshan pigs from an unselected, random-bred pig population and estimate the pigs most suitable slaughter weight. The growth development data at 20 time points of 275 Liangshan pigs (from birth to $250 \mathrm{~d}$ ) were collected. To analyze the relative gene expression related to development, seven slaughter weight phases $(50,58,66,74,82,90$, and $98 \mathrm{~kg})(20 \mathrm{pigs}$ per phase) were examined. We found that the Liangshan pig growth curve fit the typical S-curve well and that their growth turning point was 193.4 days at a weight of $62.5 \mathrm{~kg}$, according to the best fit Von Bertalanffy model based on the goodness of fit criteria. Furthermore, we estimated that the most suitable slaughter weight was 62.5 to $74.9 \mathrm{~kg}$ based on the growth curve and the relative expression levels of growth-related genes. (Key Words: Liangshan Pig, Growth Development, Growth Curve, Non-linear Model, Slaughter Weight)
\end{abstract}

\section{INTRODUCTION}

The Liangshan pig, a traditional small-sized Chinese breed, is mainly distributed in Yi Autonomous Prefecture of Liangshan at an altitude of 1,500 to $2,500 \mathrm{~m}$; it exhibits cold and coarse feeding resistance, and superior meat quality (Jones et al., 1998). Owing to its poor growth performance and carcass composition, it is now in danger of extinction. In recent years, the Liangshan pig has been included in the national preservation program for autochthonous breeds. To utilize this precious genetic resource, it is necessary to study the pig's basic parameters.

\footnotetext{
* Corresponding Authors: Shunhua Zhang. Tel: +86-18683 535030, Fax:+86-08352886080, E-mail: 363445986@qq.com / Li Zhu. Tel: +86-13982083385, E-mail: zhuli7508@163.com

2 Department of Agricultural, Food and Nutritional Science, University of Alberta, Edmonton, Alberta T6G 2P5, Canada.

${ }^{3}$ Mabian Gold LiangShan Agricultural Development Co., LTD, Mabian, Sichuan 614600, China.

${ }^{4}$ Sichuan Tequ Investment Group Ltd Co., Chengdou 610200, China.

${ }^{a}$ These authors contributed equally to this work.

Submitted Jan. 5, 2015; Revised Mar. 17, 2015; Accepted Apr. 8, 2015
}

So far, there are no such reports on their growth development and characteristics at different slaughter weights.

Swine growth models have the potential to influence alternative management decisions and identify alternative strategies to improve swine production efficiency (Schinckel and De Lange, 1996). The pig's growth potential must be accurately characterized to effectively apply these models (Craig and Schinckel, 2001). The process of growth measured as body mass or body weight on a longitudinal time frame has often been summarized using mathematical equations fitted to growth curves. Correct specification of the growth model is important for the appropriateness of the subsequent analysis. Thus, a general goodness-of-fit testing method for growth curve models is likely to have immense practical value. One of the objectives of curve fitting is to describe body weight increases over time or with age using biologically interpretable mathematical parameters. Growth curves vary among different species, especially in native breeds where growth is often delayed. In western pigs, the live body weight range most desired by the market is 110 to $120 \mathrm{~kg}$ (Boland et al., 1996). Understanding the biology of model parameters and their relationships provides a sound 
basis for developing a breeding strategy to modify or change the trajectory of growth. Growth trend parameters are highly heritable and are successfully used in selection studies. Studies have pointed out that the purpose of growth curve fitting is to describe the course of mass increase with age by simple equations with a few parameters (Ricklefs, 1985). They are important not only as selection criteria but also in terms of feed management techniques used during the production period to achieve slaughter weight. Other research has determined the optimum slaughter date for pigs kept on different energy diets with the aim of maximum utilization of the meat growth potential, while simultaneously achieving greater economic benefits (Kuhn et al., 1987). Knowing the parameters in some models enables us to predict the future live weights of animals or their tissues and organs, and allows good predictions of the time needed to obtain a predefined live weight.

The asymmetric S-function, a generalized logistic equation with a variable inflection point, has proved appropriate in describing boar growth during the fattening period (Kralik et al., 1993). Growth functions can be grouped into three categories: those that only represent diminishing returns behavior (e.g., monomolecular, exponential with abrupt cut-off), those describing a fixed point of inflection (e.g., Gompertz, logistic), and those encompassing a variable (flexible) point of inflection (e.g., von Bertalanffy, Richards). The flexible functions are generalized models that encompass simpler models for particular values of an additional parameter.

Moreover, many studies have reported the effect of slaughter weight on growth development and carcass quality (Correa et al., 2006), but few reports have compared the relative expression levels of growth-related genes at different slaughter weights. The melanocortin-4 receptor $(M C 4 R)$ gene has been implicated in regulating feeding behavior and body weight (Marsh et al., 1999). Analyses of growth and performance test records revealed significant associations between $M C 4 R$ genotypes and backfat thickness, growth rate, and overall feed intake (Kim et al., 2000). Insulin-like growth factor I $(I G F 1)$ is the main regulator of postnatal somatic growth, stimulating anabolic processes such as cell division, skeletal growth, and protein synthesis (Curi et al., 2005). Pituitary specific transcription factor-1 (PIT1) regulates growth hormone, prolactin, and thyroid-stimulating hormone 6 in several mammals. Therefore, PIT1 was chosen as a candidate gene to investigate its association with growth and carcass traits in pigs (Yu et al., 1995). Leptin ( $L E P$ ) has been implicated in the regulation of food intake, energy expenditure, and whole-body energy balance (Houseknecht et al., 1998). Myostatin (MSTN), a member of the transforming growth factor-beta $(T G F-\beta)$ family of signaling molecules, regulates the growth and force generation of skeletal muscle
(Patel and Amthor, 2005). Growth hormone 1 (GHI) is known for its indispensable action in promoting growth and regulating energy metabolism (Goodman, 1993).

The objective of this study was to examine the growth and development of the Liangshan pig by fitting its growth curve with three non-linear models. To estimate the most suitable slaughter weight of the Liangshan pig, we analyzed the differences in the relative expression levels of several growth and carcass-related genes in seven different growth phases.

\section{MATERIALS AND METHODS}

All animal procedures were conducted in accordance with institutional guidelines for the care and use of laboratory animals was approved by the Animal Care and Ethics Committee of Sichuan Agricultural University, Sichuan, China, under Permit number DKY-S20123030.

\section{Animals and treatment}

The experiment was organized by Sichuan Agricultural University and conducted on the Liangshan pig preservation farm in Mabian Gold Liangshan Agricultural Development Co., Ltd. The growth development data at 20 time points of 275 captive Liangshan pigs with similar date and weight at birth were collected from birth to $250 \mathrm{~d}$ in an unselected, random mating population. Feed conversion rate (FCR), daily feed intake (DFI), and growth weight were measured to fit the growth curve by three non-liner models. The pigs with the same days were housed in individual pens $\left(2 \mathrm{~m}^{2}\right)$ located in the same room. The DFI is the average weight of the room. Calculation formula: average DFI = daily consumption/the number of pigs. All pigs were fed twice daily with the same diet, and had ad libitum access to feed and water (nipple drinkers). The experimental diets, based on corn and soybean meal, were formulated with crude protein concentrations, trace minerals, and vitamins to meet or exceed the National Research Council (NRC, 1998) recommendations for the different growth phases. During the experimental period, the corn-soybean meal diet was offered to pigs as shown in Table 1. A total of 140 male (barrow) pigs were randomly selected for gene expression samples. We set up seven different growth phases $(50 \mathrm{~kg}, 58$ $\mathrm{kg}, 66 \mathrm{~kg}, 74 \mathrm{~kg}, 82 \mathrm{~kg}, 90 \mathrm{~kg}$, and $98 \mathrm{~kg}$ respectively, 20 pigs per phase, all the pigs were randomly selected from the group), all the actual body weight and phases situations were shown in Table 2. When the pigs had reached their target weights, they were transported to a commercial abattoir. After the pigs had rested for approximately $24 \mathrm{~h}$ at the abattoir, they were ready for slaughter. On the day of slaughter, the pigs were electrically stunned $(90 \mathrm{~V}, 10 \mathrm{~s}, 50$ $\mathrm{Hz}$ ), exsanguinated, dehaired, and eviscerated. After slaughter, the right side of the carcass was used for 
Table 1. Ingredients and nutritional composition of the basal experiment diets

\begin{tabular}{lcc}
\hline Item & 20 to $50 \mathrm{~kg}$ & 50 to $90 \mathrm{~kg}$ \\
\hline Ingredients $(\mathrm{g} / \mathrm{kg})$ & 700 & 772 \\
$\quad$ Corn & 270 & 200 \\
Soybean & 9 & 8 \\
CaHPO $_{4}$ & 8 & 7 \\
Limestone & 3 & 3 \\
Salt & 0.3 & - \\
Lysine & 10 & 10 \\
Premix & \\
Nutritional composition & & \\
DE $(\mathrm{MJ} / \mathrm{kg})$ & 13.9 & 13.83 \\
CP $(\mathrm{g} / \mathrm{kg})$ & 180 & 154 \\
Ca $(\mathrm{g} / \mathrm{kg})$ & 6 & 5.2 \\
P $(\mathrm{g} / \mathrm{kg})$ & 5 & 4.6 \\
Lysine $(\mathrm{g} / \mathrm{kg})$ & 9.5 & 7.5 \\
\hline
\end{tabular}

$\mathrm{DE}$, digestible energy; $\mathrm{CP}$, crude protein.

${ }^{1}$ Provided the following (unit/kg): 1,600 mg of $\mathrm{Cu} ; 10,000 \mathrm{mg}$ of $\mathrm{Fe}$; $3,000 \mathrm{mg}$ of $\mathrm{Mn} ; 10,000 \mathrm{mg}$ of $\mathrm{Zn} ; 40 \mathrm{mg}$ of I and $30 \mathrm{mg}$ of Se; 605,000 IU of vitamin $A ; 155,000 \mathrm{IU}$ of vitamin $\mathrm{D}_{3} ; 1,800 \mathrm{IU}$ of vitamin $\mathrm{E} ; 200$ $\mathrm{mg}$ of vitamin $\mathrm{K}_{3} ; 300 \mathrm{mg}$ of vitamin $\mathrm{B}_{1} ; 400 \mathrm{mg}$ of riboflavin; $200 \mathrm{mg}$ of vitamin $\mathrm{B}_{6} ; 1.5 \mathrm{mg}$ of vitamin $\mathrm{B}_{12} ; 1,500 \mathrm{mg}$ of pantothenic acid; 2,800 $\mathrm{mg}$ of niacin; $12,500 \mathrm{mg}$ of choline.

All data were analyzed values except $\mathrm{DE}$, which was calculated using swine National Research Council (1998) values.

segmentation to measure backfat, dressing percentage, and carcass lean. Every pig was slaughtered and decomposed into lean meat, bone and fat, and then the lean meat percentage was calculated according to the actual weight. The left one was used for sample collection. The samples were obtained from the core of the longissimus dorsi (LD) adjacent to the last rib from the left side carcass immediately after exsanguination, and rapidly frozen in liquid nitrogen for the detection of gene expression.

\section{Growth curve models}

There are three nonlinear models involved in our study. The first is the logistic growth curve model, the equation is $\mathrm{W}_{\mathrm{t}}=\mathrm{A} /\left(1+\mathrm{B} e^{-k t}\right)$. The second is the Gompertz growth curve model, defined by the equation $\mathrm{W}_{\mathrm{t}}=\mathrm{A} e^{-B e^{-k t}}$. The third is the Von Bertalanffy growth curve model, which is defined

Table 2. Information of Liangshan pigs being slaughtered

\begin{tabular}{lcccc}
\hline Phases & Number & $\begin{array}{c}\text { Growth } \\
\text { days }\end{array}$ & $\begin{array}{c}\text { Slaughter weight } \\
\text { expected }(\mathrm{kg})\end{array}$ & $\begin{array}{c}\text { Slaughter weight } \\
\text { reality }(\mathrm{kg})\end{array}$ \\
\hline 1 & 20 & 160 & 50 & $53.2 \pm 1.37$ \\
2 & 20 & 171 & 58 & $59.5 \pm 0.86$ \\
3 & 20 & 195 & 66 & $67.4 \pm 2.11$ \\
4 & 20 & 216 & 74 & $74.9 \pm 1.25$ \\
5 & 20 & 228 & 82 & $80.4 \pm 1.00$ \\
6 & 20 & 240 & 90 & $86.7 \pm 0.79$ \\
7 & 20 & 254 & 98 & $91.5 \pm 1.85$ \\
\hline
\end{tabular}

by the equation $\mathrm{W}_{\mathrm{t}}=\mathrm{A} \times\left(1-\mathrm{B} e^{-k t}\right)^{3}$. When fitting a curve by these models, $\ln B / k, \ln B / k$, and $\ln B / k$ represent the inflection age; $\mathrm{A} / 2, \mathrm{~A} / \mathrm{e}$, and $8 \mathrm{~A} / 27$ represent the inflection weight; $\mathrm{kw} / 2, \mathrm{kw}$, and $3 \mathrm{kw} / 2$ represent the maximum daily gain. In the above equations, $\mathrm{W}_{\mathrm{t}}$ represents the time point where the weight was recorded, A represents the maximum size, $\mathrm{k}$ may be interpreted as the inherent relative growth rate at the start, and $\mathrm{B}$ is the growth curve line constant.

Goodness-of-fit $\left(\mathrm{R}^{2}\right)$ was used to judge the merits of the fitting model, the equation is $\mathrm{R}^{2}=1-\frac{\mathrm{RSE}}{\mathrm{RST}}$, where $\mathrm{R}^{2}$ represents the goodness-of-fit, RSE represents the residual sum of squares, and RST represents the sum of squares of deviations.

\section{Real-time polymerase chain reaction analysis}

Samples were obtained from the core of the LD adjacent to the last rib from the left side of carcass immediately after exsanguination. The samples for gene expression were promptly frozen in liquid nitrogen and stored at $-80^{\circ} \mathrm{C}$ until subsequent analyses. The relative expression levels of selected genes were quantified using real-time RTpolymerase chain reaction (PCR) analysis. Briefly, total RNA was extracted using TRIZOL reagent (Invitrogen Corp, Carlsbad, CA, USA) according to the manufacturer's instructions. Reverse transcription was performed using oligo (dT) random 6-mers primers provided in the PrimeScript RT Master Mix kit (TaKaRa, Dalian, China), following the manufacturer's recommendations. Quantitative PCR was performed using the SYBR Premix Ex Taq kit (TaKaRa, China) on a CFX96 Real-Time PCR detection system (Bio-Rad, Richmond, CA, USA). All measurements contained a negative control (no cDNA template) and each RNA sample was analyzed in triplicate. Relative expression levels of the target mRNAs were calculated using the $\Delta \Delta \mathrm{Ct}$ method (Livak and Schmittgen, 2001).

\section{Statistical analyses}

All experimental data were preliminary processed by Excel 2007. Statistical analyses were performed using the analysis of variance (ANOVA) procedure of SAS System (SAS 9.2; SAS Inst. Inc., Cary, NC, USA). All of the data were analyzed using one-way ANOVA, the factor was slaughter weight. Tukey-Kramer test was applied to post hoc test. Values are expressed as means \pm standard error of the mean. Differences were considered statistically significant if $\mathrm{p}<0.05$.

\section{RESULTS AND DISCUSSION}

\section{Lianshan pig growth curve}

The three non-liner models we used to estimate the 
Table 3. The measured and estimated value of the body weight of Liangshan pig produced by different curve models

\begin{tabular}{|c|c|c|c|c|c|c|c|c|}
\hline \multirow{2}{*}{ Day } & \multicolumn{2}{|c|}{ Measured value } & \multicolumn{2}{|c|}{ Von Bertalanffy } & \multicolumn{2}{|c|}{ Logistic } & \multicolumn{2}{|c|}{ Gompertz } \\
\hline & Weight (kg) & $\mathrm{ADG}(\mathrm{g})$ & Weight (kg) & $\mathrm{ADG}(\mathrm{g})$ & Weight (kg) & $\mathrm{ADG}(\mathrm{g})$ & Weight (kg) & ADG (g) \\
\hline$\overline{0}$ & 0.77 & & 1.16 & & 4.13 & & 2.17 & \\
\hline 21 & 3.33 & 121.90 & 3.44 & 108.65 & 6.03 & 90.69 & 4.26 & 99.76 \\
\hline 28 & 4.00 & 95.71 & 4.51 & 153.75 & 6.83 & 114.39 & 5.21 & 135.12 \\
\hline 48 & 7.20 & 160.00 & 8.46 & 197.22 & 9.69 & 142.98 & 8.69 & 174.21 \\
\hline 58 & 10.91 & 371.00 & 10.89 & 243.53 & 11.49 & 180.07 & 10.89 & 220.22 \\
\hline 88 & 22.68 & 392.33 & 19.84 & 298.06 & 18.71 & 240.64 & 19.35 & 282.04 \\
\hline 94 & 24.10 & 236.67 & 21.88 & 340.97 & 20.52 & 301.31 & 21.36 & 334.57 \\
\hline 100 & 25.40 & 216.67 & 24.00 & 353.25 & 22.46 & 322.66 & 23.46 & 350.38 \\
\hline 120 & 29.72 & 216.00 & 31.53 & 376.47 & 29.82 & 368.36 & 31.08 & 380.70 \\
\hline 130 & 31.43 & 171.00 & 35.52 & 398.91 & 34.00 & 417.59 & 35.18 & 409.87 \\
\hline 150 & 42.13 & 535.00 & 43.83 & 415.58 & 43.12 & 456.19 & 43.78 & 430.22 \\
\hline 160 & 49.19 & 706.00 & 48.11 & 427.94 & 47.94 & 481.63 & 48.21 & 443.34 \\
\hline 180 & 56.55 & 368.00 & 56.82 & 435.38 & 57.67 & 486.66 & 57.17 & 447.78 \\
\hline 190 & 62.28 & 573.00 & 61.21 & 439.28 & 62.42 & 474.44 & 61.63 & 445.89 \\
\hline 200 & 66.88 & 460.00 & 65.61 & 439.76 & 66.98 & 455.67 & 66.04 & 440.86 \\
\hline 210 & 70.13 & 325.00 & 70.00 & 438.82 & 71.28 & 430.36 & 70.37 & 433.38 \\
\hline 220 & 75.09 & 496.00 & 74.36 & 436.59 & 75.28 & 400.06 & 74.61 & 423.77 \\
\hline 230 & 79.26 & 417.00 & 78.70 & 433.19 & 78.94 & 366.45 & 78.73 & 412.35 \\
\hline 240 & 81.72 & 246.00 & 82.98 & 428.76 & 82.26 & 331.16 & 82.73 & 399.45 \\
\hline 250 & 86.80 & 508.00 & 87.22 & 423.40 & 85.21 & 295.64 & 86.58 & 385.35 \\
\hline
\end{tabular}

ADG, average daily gain (g).

value of Liangshan pig body weights are shown in Table 3 and Figure 1. A rapid growth period occurred between 150 to $190 \mathrm{~d}$, and the Liangshan pig growth curve and the typical S-curve were a good fit. The relative growth intensity of younger pigs was higher than that of older pigs, and it decreased gradually with age. As shown in the tables,

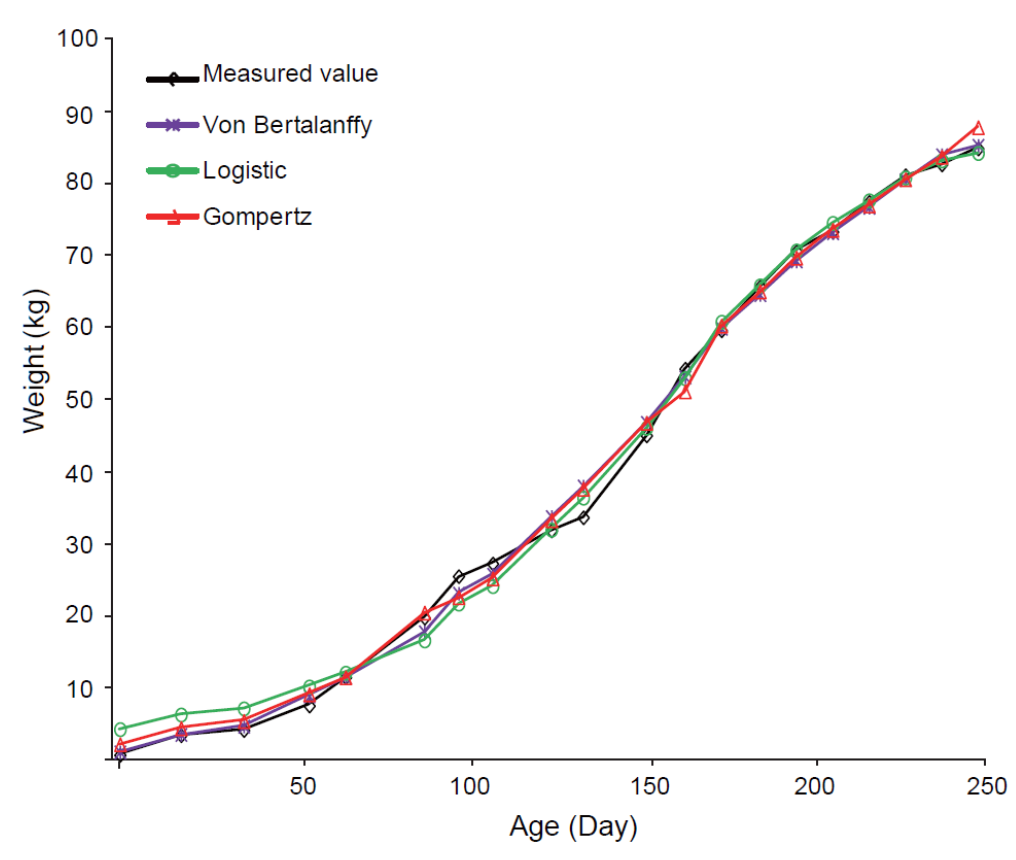

Figure 1. The actual growth curve and the fitting growth curve of different models of Liangshan pig. the fitted lines from all models were very close to the observed real values and the models could be ranked according to their $\mathrm{R}^{2}$ values as Von Bertalanffy $(0.9971)$, Gompertz (0.9968), and logistic (0.9947). The inflection point of the growth curve suggested that Liangshan pigs reached their maximum growth rate at day 193.4 and the 
average body weight at this time was $62.5 \mathrm{~kg}$, after which the growth rate slowed down. The maximum growth rate was $455.43 \mathrm{~g} / \mathrm{d}$, much lower than Large White, which is $659.08 \mathrm{~g} / \mathrm{d}$ (Dube et al., 2014). The above results were consistent with other reports on Chinese native pigs, the inflection point weight of the Tibetan pig is $29.73 \mathrm{~kg}$ with $180.0 \mathrm{~g}$ in maximal daily gain and in the Chenghua pig is $77.73 \mathrm{~kg}$ with $430.0 \mathrm{~g}$ in maximal daily gain (Hao et al., 2007). Previous research has shown that ADG decreased with increasing slaughter weight and found a reduction in growth rate the heavier the slaughter weight, which explains the deterioration in feed efficiency (Neely et al., 1979; Kanis et al., 1990; Ellis et al., 1996; Candek-Potokar et al., 1997). In the present study, the Liangshan pig exhibited poor growth performance, thus, their slaughter weight should be much lower than many western commercial pigs (Bazer et al., 1988a,b). According to these results, we can conclude that the suitable slaughter weight of the Liangshan pig $>62.5 \mathrm{~kg}$. Since the Liangshan pig belongs to an endangered variety and the population is quite small, the sample used in our study was not big enough, that is, the above results needed more data for validation. If possible, we will expand the numbers in the future.

\section{Liangshan pig growth and carcass traits}

Growth rate, FCR, and lean meat percentage of the Liangshan pig are shown in Figure 2. The growth rate increased greatly in the early growth phase and remained steady in the intermediate phases (from the third to fifth phases), then declined slowly. The FCR began to rise slowly from the third phase $(67.4 \mathrm{~kg}$ weight), that means the feed efficiency began to decline. The lean meat percentage was $43.81 \pm 2.09 \%$, higher in the earlier stage and increased rapidly from approximately $67.4 \mathrm{~kg}$ (the third phase) and $74.9 \mathrm{~kg}$ (the fourth phase), then gradually decreased. These results were consistent with other reports, which found that superior phenotypes occur in the intermediate phase (Latorre et al., 2004; Heyer and Lebret, 2007). The turning point of the Liangshan pig's growth rate, FCR, and carcass lean percentage occurred in either the third (67.4 kg body weight) or fourth growth phase $(74.9 \mathrm{~kg}$ body weight). This is similar to previous research in which the growth rate, FCR, and lean meat declined as slaughter weight increased in the later period (Ellis et al., 1996; Latorre et al., 2004). That is, the suitable slaughter weight of the Liangshan pig is 67.4 to $74.9 \mathrm{~kg}$.

\section{Expression patterns of growth and carcass trait related genes}

The relative expression level of several genes related to growth and carcass quality are shown in Figure 3. The expression patterns of $I G F 1, P I T 1$, and GH1 in the growth and development of the Liangshan pig were quite similar,
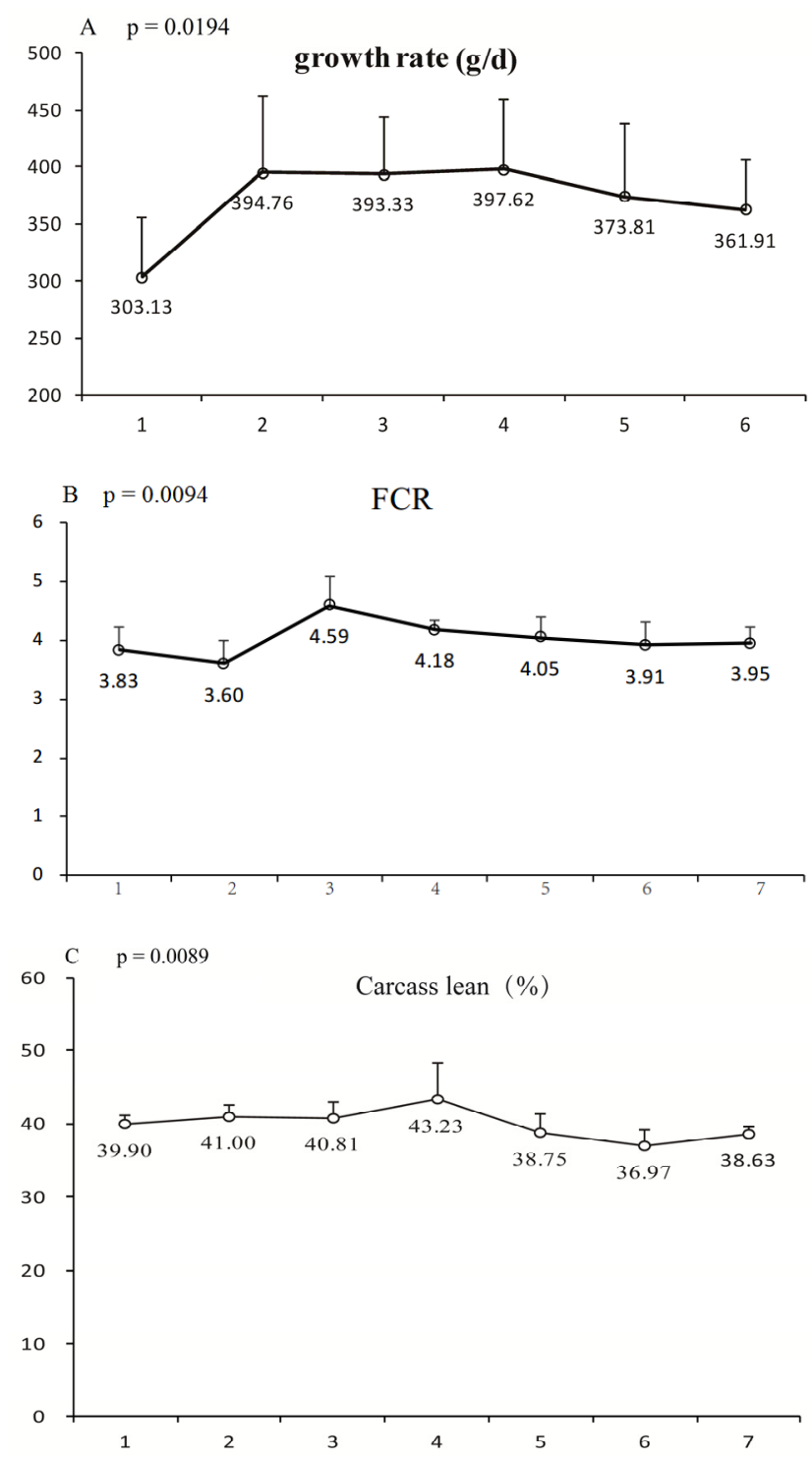

Figure 2. Growth rate, feed conversion rate (FCR) and carcass lean percentage of Liangshan pig. (A) growth rate (B) FCR and (C) carcass lean percentage. $\mathrm{x}$-coordinate 1 to 7 mean the slaughter weight phases.

with higher expression in the intermediate slaughter weight growth phases $(67.4 \pm 2.11 \mathrm{~kg}, 74.9 \pm 1.25 \mathrm{~kg}$, and $80.4 \pm 1.00$ $\mathrm{kg})$ than other phases $(\mathrm{p}<0.05)$. These results were in agreement with previous studies on growth and carcass traits (Yu et al., 1995; Curi et al., 2005; Dandan et al., 2014). LEP and MSTN gene expression in the intermediate weight phase was significantly lower than in other phases $(p<0.05)$, consistent with the growth development curve. Leptin, encoded by the $L E P$ gene, is a hormone that acts as a signal of satiety affecting feed intake, energetic balance, and body composition (Pérez-Montarelo et al., 2011). Its relative expression level was low in the intermediate phases because of the higher energy needs for high-speed growth. A previous study found that MSTN might be a candidate gene for muscular hypertrophy and may regulate muscle 
A

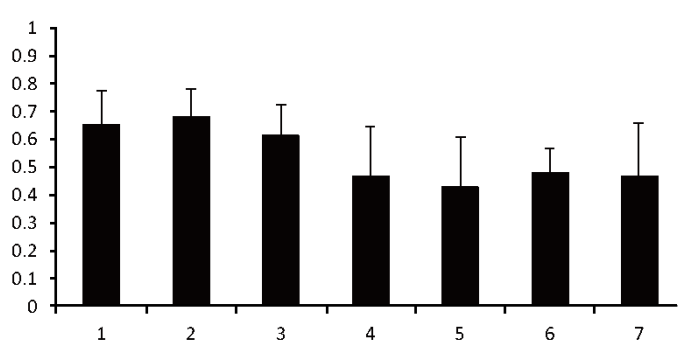

C

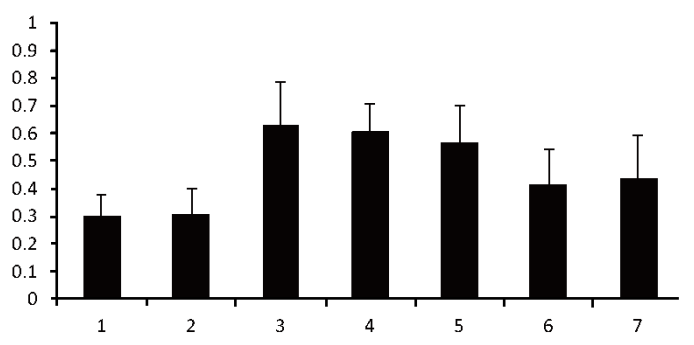

$E$

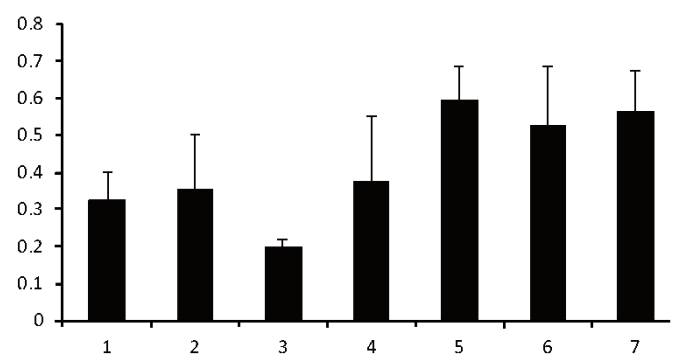

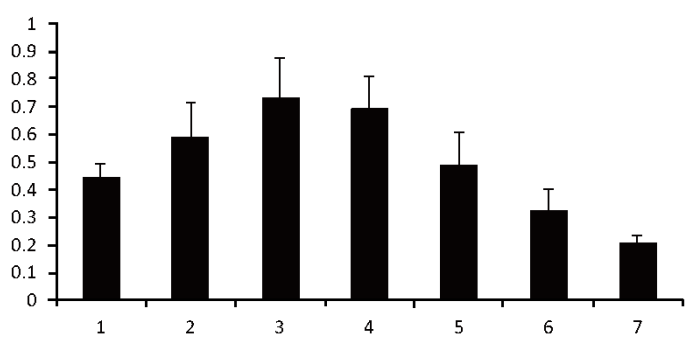

D

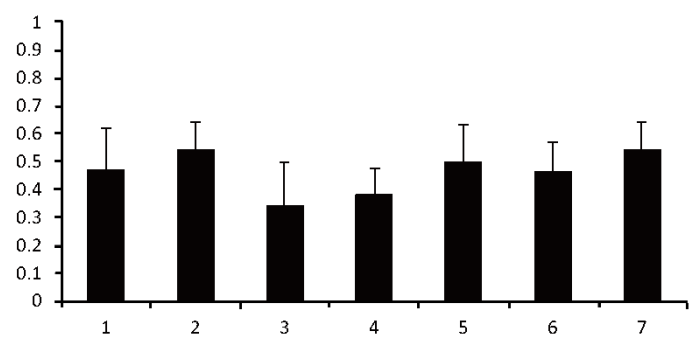

GH1

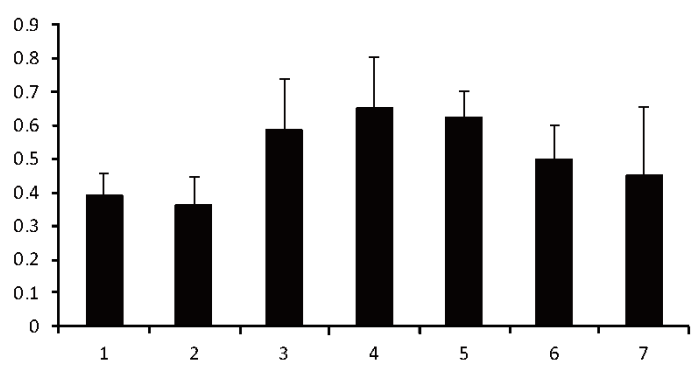

Figure 3. The relative expression level of several genes related to growth and development. (A) The melanocortin-4 receptor (MC4R), (B) Insulin-like growth factor I (IGF1), (C) Pituitary specific transcription factor-1 (PIT1), (D) Leptin (LEP), (E) Myostatin (MSTN), (F) Growth hormone $1(G H 1)$. Gene expression levels represent the relative mRNA expression compared to the controls. Values represent the mean \pm standard error, all are normalized by the maximum value.

development (Stinckens et al., 2008). We speculate that muscle develops faster in the intermediate weight phase than in other phases, which is consistent with the carcass lean variation in the different growth phases in our study. $M C 4 R$ expression was higher in all slaughter weight phases, the relative expression in the fourth and fifth phase were significantly lower than in the first, second, and third phases $(p<0.05)$, but there was no significant difference between it and the other phases. Other reports have studied $M C 4 R$ as a candidate gene for growth control and performance traits in the pig (Kim et al., 2000; Ovilo et al., 2006). For example, $M C 4 R$ was associated with increased DFI, daily gain, and backfat thickness, and decreased lean meat content (Piórkowska et al., 2010). Therefore, its expression was higher at all slaughter weights but lower in the intermediate weight phases because muscle development was fast at this time. According to the above analysis, we speculate that the suitable slaughter weight of the Liangshan pig occurs in the third $(67.4 \pm 2.11 \mathrm{~kg})$ to the fourth phases $(74.9 \pm 1.25 \mathrm{~kg})$.

\section{Conclusions}

Our study utilized three non-linear growth models to fit the growth curve of the Liangshan pig from an unselected, random pig population. Von Bertalanffy was the best for achieving a real observation model to fit the Liangshan pig growth curve. According to the Von Bertalanffy model, the Liangshan pig growth turning point was day 193.4, with a weight of $62.5 \mathrm{~kg}$. Backfat, dressing, and lean percentage implied that the third phase was the optimal slaughtering stage. The gene expression results revealed significant associations between the relative $M C 4 R, I G F 1$, and $L E P$ expression levels and growth and carcass traits. Overall, considering the growth curve and gene expression results, we conclude that the most suitable slaughter weight of the Liangshan pig is 62.5 to $74.9 \mathrm{~kg}$.

\section{ACKNOWLEDGMENTS}

This study was supported by the earmarked fund for China Agriculture Research System (No. CARS-36-05B), 
the Chinese national Sci \& Tech Support Program (No. 2013BAD20B07), and the Sichuan Sci \& Tech Support Program (No. 2012NZ001, and 2013NZ0041).

\section{REFERENCES}

Bazer, F. W., W. W. Thatcher, F. Martinat-Botte, and M. Terqui. 1988a. Conceptus development in Large White and prolific Chinese Meishan pigs. J. Reprod. Fertil. 84:37-42.

Bazer, F. W., W. W. Thatcher, F. Martinat-Botte, and M. Terqui. 1988b. Sexual maturation and morphological development of the reproductive tract in Large White and prolific Chinese Meishan pigs. J. Reprod. Fertil. 83:723-728.

Boland, M. A., K. A. Foster, P. V. Preckel, and A. P. Schinckel. 1996. Analyzing pork carcass evaluation technologies in a swine bioeconomic model. J. Prod. Agric. 9:45-49.

Candek-Potokar, M., B. Zlender, and M. Bonneau. 1997. The effects of age and weight at slaughter on the chemical composition of loin muscle in Duroc $\times($ Landrace $\times$ Large White $)$ pigs. J. Recherche Porcine en France 29:391-396.

Correa, J. A, L. Faucitano, J. P. Laforest, J. Rivest, M. Marcoux, and C. Gariépy. 2006. Effects of slaughter weight on carcass composition and meat quality in pigs of two different growth rates. Meat Sci. 72:91-99.

Craig, B. A. and A. Schinckel. 2001. Nonlinear mixed effects model for swine growth. Prof. Anim. Sci. 17:256-260.

Curi, R. A., H. N. De Oliveira, A. C. Silveira, and C. R. Lopes. 2005. Association between IGF-I, IGF-IR and GHRH gene polymorphisms and growth and carcass traits in beef cattle. Livest. Prod. Sci. 94:159-167.

Dandan, Z., X. Lui, R. Max, Z. Zhang, S. Zhao, and B. Fan. 2014. Genome-wide association study of the backfat thickness trait in two pig populations. Front. Agric. Sci. Eng. 1:91-95.

Dube, B., S. D. Mulugeta, and K. Dzama. 2014. Genetic relationship between growth and carcass traits in Large White pigs. South Afr. J. Anim. Sci. 43:482-492.

Ellis, M., A. J. Webb, P. J. Avery, and I. Brown. 1996. The influence of terminal sire genotype, sex, slaughter weight, feeding regime and slaughter-house on growth performance and carcass and meat quality in pigs and on the organoleptic properties of fresh pork. Anim. Sci. 62:521-530.

Goodman, H. M. 1993. Growth hormone and metabolism. The Endocrinology of Growth, Development, and Metabolism in Vertebrates (Eds. M. P. Schreibman, C. G. Scanes, and T. P. Pang). Academic Press, Diego, CA, USA. 93-115.

Hao, Z., Q. Yang-zom, W. Qiang, L. Zhang, and Z. Dui. 2007. Analysis of weight growth curves in Tibetan pig. Ecol. Domest. Anim. 6:41-43.

Heyer, A. and B. Lebret. 2007. Compensatory growth response in pigs: Effects on growth performance, composition of weight gain at carcass and muscle levels, and meat quality. J. Anim. Sci. 85:769-778.

Houseknecht, K. L., C. A. Baile, R. L. Matteri, and M. E. Spurlock. 1998. The biology of leptin: A review. J. Anim. Sci. 76:14051420.
Jones, G., M. Rothschild, and A. Ruvinsky. 1998. Genetic aspects of domestication, common breeds and their origin. The Genetics of the Pig (Eds. M. F. Rothschild, and A. Ruvinsky). CAB International, Wallingford, UK. 17-50.

Kanis, E., G. J. Nieuwhof, K. H. De Greef, W. Van der Hel, M. W. Verstegen, J. Huisman, and P. Van der Wal. 1990. Effect of recombinant porcine somatotropin on growth and carcass quality in growing pigs: interactions with genotype, gender and slaughter weight. J. Anim. Sci. 68:1193-1200.

Kim, K. S., N. Larsen, T. Short, G. Plastow, and M. F. Rothschild. 2000. A missense variant of the porcine melanocortin-4 receptor $(M C 4 R)$ gene is associated with fatness, growth, and feed intake traits. Mamm. Genome 11:131-135.

Kralik, G., R. Scitovski, and D. Sencic. 1993. Application of asymmetric S-function for analysis of the growth of boars. Stocarstvo 47:425-433.

Kuhn, G., K. Ender, E. Otto, K. Feige, and W. Hackl. 1987. Predict the most suitable slaughter time based on the growth and fattening performance of Börgen pigs. Arch. Tierz., Berlin 30:261-269.

Latorre, M., R. Lázaro, D. Valencia, P. Medel, and G. Mateos. 2004. The effects of gender and slaughter weight on the growth performance, carcass traits, and meat quality characteristics of heavy pigs. J. Anim. Sci. 82:526-533.

Marsh, D. J., G. Hollopeter, D. Huszar, R. Laufer, K. A. Yagaloff, S. L. Fisher, P. Burn, and R. D. Palmiter. 1999. Response of melanocortin-4 receptor-deficient mice to anorectic and orexigenic peptides. Nat. Genet. 21:119-122.

Neely, J., R. Johnson, and L. Walters. 1979. Efficiency of gains and carcass characteristics of swine of two degrees of fatness slaughtered at three weights. J. Anim. Sci. 48:1049-1056.

Ovilo, C., A. Fernández, M. C. Rodríguez, M. Nieto, and L. Silió. 2006. Association of $M C 4 R$ gene variants with growth, fatness, carcass composition and meat and fat quality traits in heavy pigs. Meat Sci. 73:42-47.

Patel, K. and H. Amthor. 2005. The function of Myostatin and strategies of Myostatin blockade-new hope for therapies aimed at promoting growth of skeletal muscle. Neuromuscul. Dis. 15:117-126.

Piórkowska, K., M. Tyra, M. Rogoz, K. Ropka-Molik, M. Oczkowicz, and M. Różycki. 2010. Association of the melanocortin-4 receptor (MC4R) with feed intake, growth, fatness and carcass composition in pigs raised in Poland. Meat Sci. 85:297-301.

Ricklefs, R. E. 1985. Modification of growth and development of muscles of poultry. Poult. Sci. 64:1563-1576.

Schinckel, A. P. and C. F. De Lange. 1996. Characterization of growth parameters needed as inputs for pig growth models. J. Anim. Sci. 74:2021-2036.

Stinckens, A., T. Luyten, J. Bijttebier, K. Van den Maagdenberg, D. Dieltiens, S. Janssens, S. De Smet, M. Georges, and N. Buys. 2008. Characterization of the complete porcine MSTN gene and expression levels in pig breeds differing in muscularity. Anim. Genet. 39:586-596.

Yu, T. P., C. K. Tuggle, C. B. Schmitz, and M. F. Rothschild. 1995. Association of PIT1 polymorphisms with growth and carcass traits in pigs. J. Anim. Sci. 73:1282-1288. 